Automatic Logic Synthesis Techniques for Digital Systems 


\section{Macmillan New Electronics Series}

Series Editor: Paul A. Lynn

Rodney F. W. Coates, Underwater Acoustic Systems

M. D. Edwards, Automatic Logic Synthesis Techniques for Digital Systems

W. Forsythe and R. M. Goodall, Digital Control

C. G. Guy, Data Communications for Engineers

Paul A. Lynn, Digital Signals, Processors and Noise

Paul A. Lynn, Radar Systems

A. F. Murray and H. M. Reekie, Integrated Circuit Design

F. J. Owens, Signal Processing of Speech

Dennis N. Pim, Television and Teletext

M. J. N. Sibley, Optical Communications

P. M. Taylor, Robotic Control

G. S. Virk, Digital Computer Control Systems

Allan Waters, Active Filter Design

\section{Series Standing Order}

If you would like to receive future titles in the series as they are published, you can make use of our standing order facility. To place a standing order please contact your bookseller or, in case of difficulty, write to us at the address below with your name and address and the name of the series. Please state with which title you wish to begin your standing order. (If you live outside the United Kingdom we may not have the rights for your area, in which case we will forward your order to the publisher concerned.)

Customer Services Department, Macmillan Distribution Ltd Houndmills, Basingstoke, Hampshire, RG21 2XS, England. 


\title{
Automatic Logic Synthesis Techniques for Digital Systems
}

\author{
Martyn D. Edwards \\ Department of Computation \\ UMIST, Manchester
}

Macmillan New Electronics

Introductions to Advanced Topics

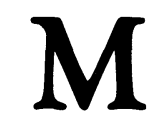

Macmillan 
All rights reserved. No reproduction, copy or transmission of this publication may be made without written permission.

No paragraph of this publication may be reproduced, copied or transmitted save with written permission or in accordance with the provisions of the Copyright, Designs and Patents Act 1988, or under the terms of any licence permitting limited copying issued by the Copyright Licensing Agency, 90 Tottenham Court Road, London W1P 9HE.

Any person who does any unauthorised act in relation to this publication may be liable to criminal prosecution and civil claims for damages.

First published 1992 by

THE MACMILLAN PRESS LTD

Houndmills, Basingstoke, Hampshire RG21 2XS

and London

Companies and representatives

throughout the world

ISBN 978-0-333-55569-9

DOI 10.1007/978-1-349-22267-4

A catalogue record for this book is available from the British Library. 


\section{Contents}

Series Editor's Foreword viii

Preface ix

1 Introduction to Design Methods and Synthesis 1

1.1 Application-specific Integrated Circuits 2

1.1.1 ASIC Design Styles 3

1.1.2 ASIC Design Methods 4

$\begin{array}{lll}1.2 & \text { Synthesis Strategies } & 7\end{array}$

1.2.1 Design Representations $\quad 7$

$\begin{array}{ll}\text { 1.2.2 What is Synthesis? } & 10\end{array}$

1.2.3 Logic Synthesis and Optimisation 11

$\begin{array}{ll}1.3 \text { Coverage of the Book } & 15\end{array}$

$\begin{array}{lll}1.4 \text { References } & 16\end{array}$

2 Review of the Logic Design Process 17

2.1 Register Transfer Level Design 17

2.1.1 Control and Data Path Sections 19

2.2 Combinatorial Logic Design 22

2.2.1 Basic Definitions 23

2.2.2 Basic Operations 26

2.2.3 Manipulation of Combinatorial Logic Functions 27

2.3 Finite State Machine Design 34

2.4 References $\quad 40$ 
3 Layout Synthesis $\quad \mathbf{4 2}$

$\begin{array}{lll}3.1 & \text { Introduction } & 42\end{array}$

3.2 Programmable Logic Arrays 43

3.2.1 PLA Folding Techniques 46

3.3 Multiple-level Logic Arrays $\quad 50$

3.3.1 MOS Design Techniques 51

3.3.2 Weinberger Array 54

$\begin{array}{lll}\text { 3.3.3 Gate Matrix } & 55\end{array}$

3.3.4 Functional Array 61

3.4 Summary $\quad 64$

3.5 References 66

4 Two-level Logic Minimisation $\quad 68$

$\begin{array}{lll}4.1 & \text { Introduction } & 68\end{array}$

$\begin{array}{lll}4.2 & \text { Heuristic Minimisation Techniques } & 77\end{array}$

4.3 Exact Minimisation Techniques 86

4.4 PLA-specific Minimisation Techniques 90

$\begin{array}{lll}4.5 & \text { Summary } & 91\end{array}$

$\begin{array}{lll}4.6 \text { References } & 92\end{array}$

5 Multiple-level Logic Synthesis $\quad 94$

$\begin{array}{lll}5.1 \text { Introduction } & 94\end{array}$

5.2 Basic Operations 96

5.2.1 Network Restructuring 97

$\begin{array}{ll}\text { 5.2.2 Division Operations } & 100\end{array}$

$\begin{array}{ll}\text { 5.2.3 Network Optimisation } & 107\end{array}$

5.2.4 Technology Mapping/Optimisation 110

$\begin{array}{lll}5.3 & \text { Specific Synthesis Systems } & 115\end{array}$

$\begin{array}{lll}\text { 5.3.1 The MIS System } & 115\end{array}$

$\begin{array}{ll}\text { 5.3.2 The BOLD System } & 119\end{array}$

$\begin{array}{lll}\text { 5.3.3 The LSS System } & 121\end{array}$

$\begin{array}{lll}\text { 5.3.4 The SOCRATES System } & 123\end{array}$

$\begin{array}{lll}\text { 5.3.5 Related Systems } & 125\end{array}$

$\begin{array}{lll}5.4 & \text { Summary } & 126\end{array}$

$\begin{array}{lll}5.5 & \text { References } & 127\end{array}$ 
6 Finite State Machine Synthesis

$\begin{array}{lll}6.1 & \text { Introduction } & 130\end{array}$

6.2 State Assignment for Two-level Logic Synthesis 132

6.2.1 Seminal Techniques 132

6.2.2 Contemporary Techniques 139

6.2.3 Alternative Techniques 148

6.3 State Assignment for Multiple-level Logic Synthesis 150

6.4 Multiple Finite State Machine Synthesis 156

$\begin{array}{lll}6.5 \text { Summary } & 159\end{array}$

6.6 References 159

7 Synthesis and Testing $\quad 163$

7.1 Review of Testing Techniques 163

7.2 Requirements for the Synthesis of Testable Circuits 169

7.3 Synthesis of Testable Combinatorial Logic Networks 170

7.4 Synthesis of Testable Finite State Machines 175

$\begin{array}{ll}7.5 \text { Summary } & 179\end{array}$

$\begin{array}{lll}7.6 \text { References } & 180\end{array}$

$\begin{array}{ll}\text { Index } & 182\end{array}$ 


\section{Series Editor's Foreword}

The rapid development of electronics and its engineering applications ensures that new topics are always competing for a place in university and polytechnic courses. But it is often difficult for lecturers to find suitable books for recommendation to students, particularly when a topic is covered by a short lecture module, or as an 'option'.

Macmillan New Electronics offers introductions to advanced topics. The level is generally that of second and subsequent years of undergraduate courses in electronic and electrical engineering, computer science and physics. Some of the authors will paint with a broad brush; others will concentrate on a narrower topic, and cover it in greater detail. But in all cases, the titles in the Series will provide a sound basis for further reading of the specialist literature, and an up-to-date appreciation of practical applications and likely trends.

The level, scope and approach of the Series should also appeal to practising engineers and scientists encountering an area of electronics for the first time, or needing a rapid and authoritative update.

Paul A. Lynn 


\section{Preface}

The use of computers to design digital systems has proved to be the philosopher's stone for systems engineers. Ever since the 1960s, when small scale integrated, SSI, silicon-based circuits consisting of a few tens of transistors were first introduced, engineers have searched for computer-aided design tools to produce efficient implementations of digital systems. Today the use of complex, very large scale integrated, VLSI, circuits consisting of hundreds of thousands of transistors makes the attainment of this goal even more important. There is an ever-increasing trend towards the use of computer-based design synthesis tools to produce physical realisations of digital systems which meet both cost and performance constraints.

In the context of this book, synthesis may be loosely defined as the automatic translation of a design description from one level of abstraction to a more detailed, lower level of abstraction. Compared to a manual synthesis process carried out by an 'expert' designer, the potential benefits are reductions in both the design time and the cost of a product, together with a 'guarantee' of circuit correctness. The main drawback with current synthesis systems is that an automatically generated circuit implementation may not be as good as one produced manually by an experienced designer - this is only really true, however, for low complexity circuits that can be created in reasonable timescales. An automatically synthesised design may have a greater silicon area and poorer performance, which may well prove to be unacceptable in an industrial context. This is especially true in the rapidly growing applicationspecific integrated circuit, ASIC, market. For example, in the home electronics industry, where ASIC components are widely used, the efficient use of silicon coupled with achievable performance is paramount.

Whereas automatic logic synthesis techniques have been known since the 1950s, in the last decade there has been a rebirth of interest in the subject. Novel automatic synthesis techniques, which have chiefly been developed in universities, are now being employed in commercially available ASIC design tools. The objective of this book is to provide an account of the 'latest' techniques for the automatic logic synthesis of digital systems realised as ASICs. The level of the material covered will be applicable to both final year 
undergraduate and postgraduate students taking VLSI design courses in Electronic Engineering and Computer Science departments. The book will also be of interest to practising engineers who wish to gain an insight into this important and expanding area.

Chapter 1 sets the scene for the book and identifies a set of tasks carried out in the ASIC design cycle. The need for computer-aided logic synthesis and optimisation tools is established. Chapter 2 presents the basic definitions necessary for an understanding of the work presented in later chapters. The chapter concentrates on design methods at the register transfer level - the usual starting point for logic synthesis tools - and the logic level. The use of familiar manual techniques for synthesising both combinatorial logic circuits and finite state machines are presented. The limitations of these techniques are highlighted, which leads to the requirements for computer-aided approaches.

Chapter 3 is concerned with the layout synthesis and optimisation of both two-level and multiple-level combinatorial logic circuits. Specifically the use of regular array techniques is discussed. Regular array layout styles can be used to provide efficient logic circuit realisations in ASIC devices.

Chapter 4 considers the development of algorithms for the minimisation of two-level combinatorial logic functions. The use of both 'exact' and 'heuristic' minimisation techniques are explored. There are situations when two-level logic circuits are not efficient in terms of silicon area utilisation and performance. In these cases, multiple-level logic implementations may produce more acceptable solutions which meet their specified constraints. Techniques for the synthesis and optimisation of multiple-level logic circuits, known as Boolean networks, are presented in chapter 5. These techniques are based on either 'algorithmic' or 'rule-based' paradigms.

Chapter 6 relates to the synthesis of finite state machines. Methods for solving the 'state assignment' problem for both two-level and multiple-level logic implementations of the combinatorial logic sections of finite state machines are presented.

Chapter 7 highlights the importance of considering the testability of ASICs at an early stage in their design cycle. The chapter provides a synopsis of testability techniques for both combinatorial logic circuits and sequential logic circuits which may be integrated into the associated synthesis process.

It should be noted that rapid advances are being made in the development of synthesis tools, which produce good quality results in all areas of the digital system design process. The signs are promising that commercial tools, which exploit these new methods, will soon become commonplace in the microelectronics applications industries. Then, perhaps, design engineers will have found their philosopher's stone.

I am very conscious of the ways in which my students have helped to clarify my ideas on this subject over the years and I am particularly grateful to my colleague, John Forrest, who has contributed his own insights. Finally, I would like to thank both Diana and Cady who, in their different ways, have provided me with love and support throughout the writing of this book. 